\title{
Ethanol in pancreatic juice after oral and intravenous administration
}

I Gjørup, S Dueholm, B Andersen, F Burcharth

\begin{abstract}
Six patients with a drain in the main pancreatic duct were studied. Ethanol was given orally with individually adjusted doses aiming at a blood value of $0.8 / 1000(17.6 \mathrm{mmol} / \mathrm{l})$. Concentrations of ethanol in venous blood and pancreatic juice were recorded for three hours. Similar studies were made when ethanol was administered as an intravenous priming dose followed by a maintenance infusion. After orally administered ethanol, pancreatic juice values were higher than those in blood for a short period of time. The relations between median concentrations and time were incongruous curves consistent with a significant treatment by time interaction. Intravenous administration resulted in a similar pattern, but the interaction was not statistically significant. These findings indicate that the human pancreas may secrete ethanol.
\end{abstract}

Our knowledge of the effects of ethanol on the pancreas is still limited, but changes in secretory

Department of Surgical Gastroenterology, Herlev Hospital, University of Copenhagen, Denmark I Gjørup

$S$ Dueholm

B Andersen

F Burcharth

Correspondence to: Dr Ida Gjørup, Department of Surgical Gastroenterology, Surgical Gastroenterology, DK-2730 Herlev, Denmark. DK-2730 Herlev, Denmark. 13 February 1990

patterns correlate well with the histopathology in chronic alcoholic pancreatitis. ${ }^{1-6}$

Animal experiments suggest that ethanol infused into the stomach or jejunum results in similar ethanol concentrations in pancreatic juice and arterial blood. The presence of ethanol in the pancreatic secretion may be a contributory cause of pancreatitis.? We therefore investigated ethanol concentrations in human pancreatic juice and blood after both oral and intravenous administration.
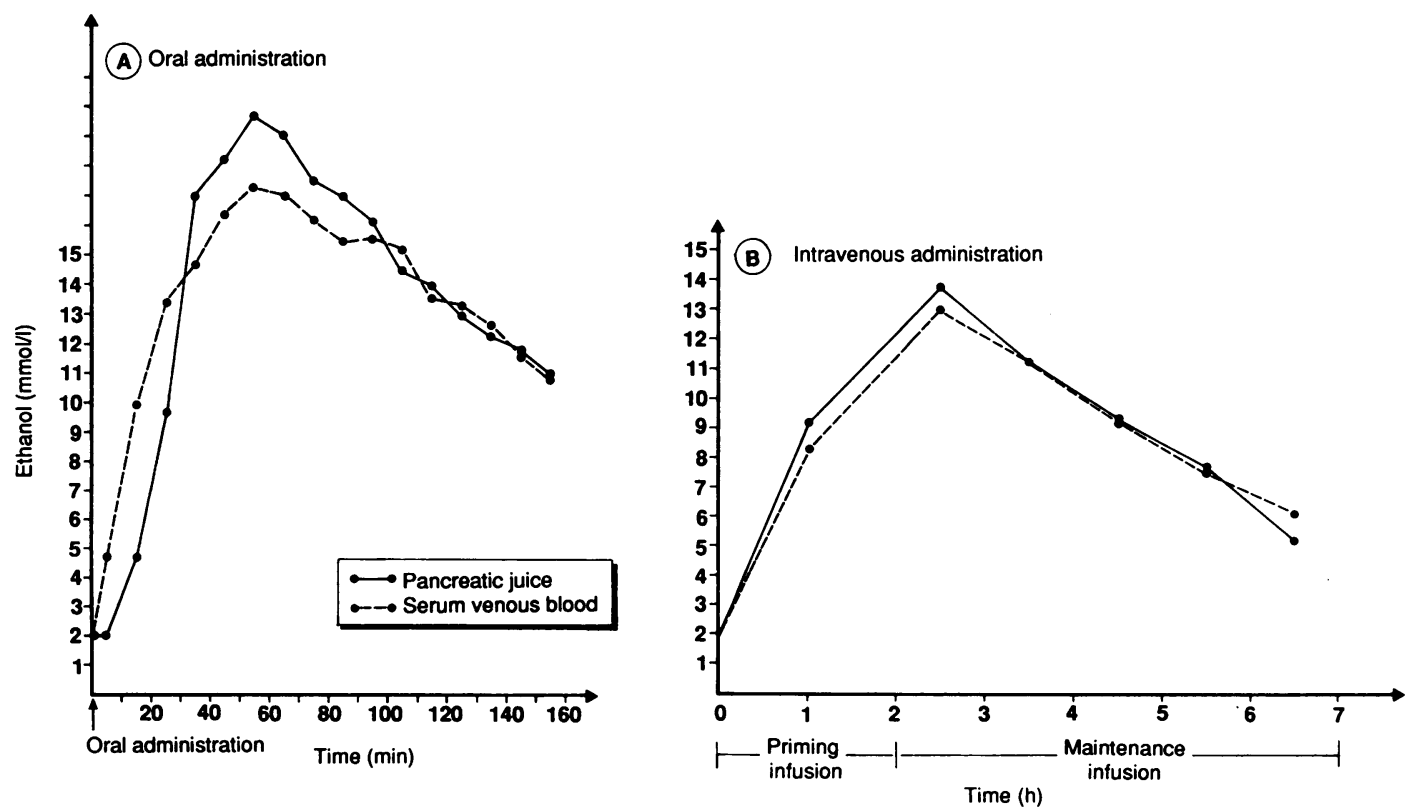

Figure 1: (A) The ethanol concentrations in pancreatic juice and in blood after oral administration of ethanol. (B) The ethanol concentrations in pancreatic juice and in blood after intravenous administration of ethanol.

\section{Methods}

Pure pancreatic juice was collected by tube drain from six male patients (age range 43-63 years). In three patients drains were inserted percutaneously into pancreatic pseudocysts which were known to communicate with the main pancreatic duct. Three had been placed in the main pancreatic duct during pancreatoduodenectomy for cancer (Whipple's operation). The reconstruction was an end to end pancreaticojejunostomy and an end to side gastrojejunostomy, the two anastomoses being $40 \mathrm{~cm}$ apart and the choledochojejunostomy in between. Our investigations were performed 12 14 days after catheter insertion, when pancreatic secretion was stable and exceeded $200 \mathrm{ml} / 24$ hours.

The study was in accordance with the Second Declaration of Helsinki. Informed consent was obtained from patients and the protocol was approved by the regional ethical committee.

\section{ORAL ADMINISTRATION OF ETHANOL}

The patients drank $0.55 \mathrm{~g}$ ethanol $/ \mathrm{kg}$ in an aqueous solution within 10 minutes. We aimed at a peak blood ethanol concentration of $0 \cdot 8 / 1000$ $(17 \cdot 6 \mathrm{mmol} / \mathrm{l})$. The mean ethanol concentrations in samples of pancreatic juice and in serum (venous blood) were assessed every 10 minutes for three hours.

INTRAVENOUS ADMINISTRATION OF ETHANOL The following day, ethanol was given intra- 

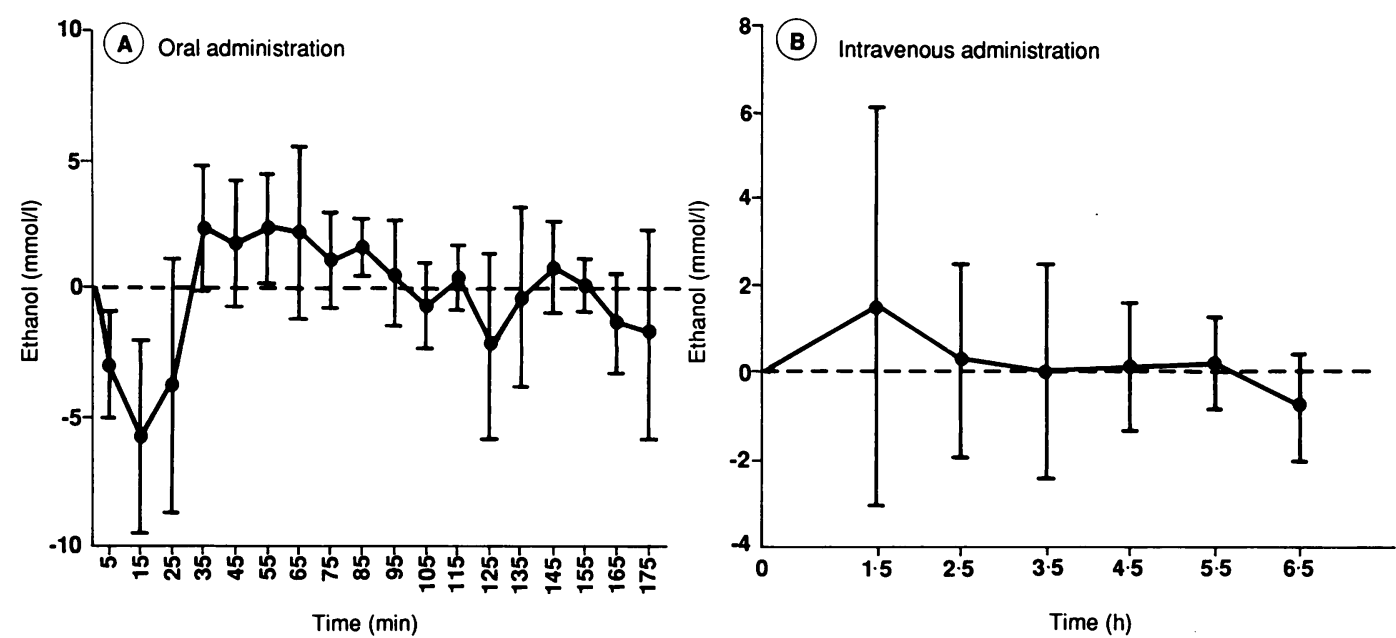

Figure 2: (A) Differences between ethanol concentrations in pancreatic juice and in venous blood (mean $\pm 95 \%$ confidence intervals) after peroral administration of $0.55 \mathrm{~g}$ ethanol/kg in six men with a drain in the main pancreatic duct. (B) Differences between ethanol concentrations in pancreatic juice and in venous blood (mean $\pm 95 \%$ confidence intervals) after intravenous administration of $0.72 \mathrm{~g}$ ethanol/kg as priming dose and $0.083 \mathrm{~g}$ ethanol/kg/hour as maintenance dose in six men with a drain in the main pancreatic duct.

venously in an amount calculated to provide and maintain a constant serum concentration of $17 \cdot 6$ $\mathrm{mmol} / \mathrm{l}$ for several hours. A priming dose of $0.72 \mathrm{~g}$ ethanol $/ \mathrm{kg}$ was given via infusion pump over two hours, followed by $0.083 \mathrm{~g}$ ethanol $/ \mathrm{kg} /$ hour. ${ }^{8}$ Concentrations of ethanol in venous blood and in pancreatic juice were measured for five hours.

Ethanol concentrations in serum and pancreatic juice were measured by gas liquid chromatography (detection concentration $=2$ $\mathrm{mmol} / 1$, coefficient of variation $=0 \cdot 02$, and $\mathrm{SD}=$ $1 \cdot 35 \mathrm{mmol} / \mathrm{l})$.

\section{STATISTICAL ANALYSIS}

The statistical methods used were analysis of variance (ANOVA) for a two factor design: time and ethanol concentrations with repeated measurements of each. Owing to uncertainties with regard to distributional assumptions, both the usual parametric ANOVA and a nonparametric model were used. ${ }^{9}$ Statistical significance was assigned to all $\mathrm{p}$ values below 0.05 . Problems with regard to interpretation of insignificant outcomes were approached through $95 \%$ confidence intervals for pair wise differences (Figs 2(A) and (B)).

\section{Results}

ORAL ADMINISTRATION

The ethanol concentrations in pancreatic juice and blood after oral ethanol administration are shown in Figure 1(A). A statistically significant interaction was found between the two factors $(p<0 \cdot 01)$. Ethanol concentrations were higher in pancreatic juice than in venous blood for a period ranging from approximately 30 to 90 minutes after ingestion (Fig 2(A)). The median ethanol concentrations in blood at 10,50, and 120 minutes were $6 \mathrm{mmol} / \mathrm{l}, 16 \mathrm{mmol} / \mathrm{l}$, and 11.5 $\mathrm{mmol} / \mathrm{l}$, respectively. and in blood after intravenous ethanol administration are shown in Figure 1(B). Figure 2(B) shows that a comparable pattern was evident also when ethanol was given as an intravenous maintenance infusion, but the interaction component of ANOVA was not statistically significant $(p \approx 0 \cdot 07)$. Variations over time were highly significant $(p<0.001)$. The median ethanol concentrations in blood at two, four, and six hours were $15 \mathrm{mmol} / \mathrm{l}, 11 \mathrm{mmol} / \mathrm{l}$, and $7.5 \mathrm{mmol} / \mathrm{l}$, respectively.

\section{Discussion}

Ethanol leaves the stomach and intestine by simple diffusion. ${ }^{10}$ During constant infusion the concentrations of ethanol in arterial and venous blood are identical after two hours. Before ethanol enters the systemic arterial circulation there is a loss due to liver metabolisation and subsequent pulmonary elimination. ${ }^{10}$ Since ethanol diffuses easily across capillary walls the physical principles for the distribution among blood, tissues, and body fluids are those governing the absorption into the blood. ${ }^{10}$

After oral administration the concentrations of ethanol in canine pancreatic juice ${ }^{11}$ and in human saliva $^{12}$ are the same as in the respective sera. We found, however, a higher concentration of ethanol in pancreatic juice than in venous blood. It has been suggested that the ethanol concentration in various tissues depends only upon their relative water content. ${ }^{10}$ Whether this is the cause for the difference in ethanol concentrations in pancreatic juice and venous blood in our study remains to be elucidated.

Ethanol acts on exocrine pancreatic secretion by various mechanisms. Animal studies suggest that ethanol stimulates the exocrine pancreas by mediation of its cholinergic innervation. ${ }^{13}$ It is known that ethanol induces release of gastrin and vasoactive intestinal polypeptide, which in turn stimulate the human exocrine pancreas. $^{14}$ is

Studies of ethanol metabolism in rat pancreas have shown that alcohol dehydrogenase is more concentrated in the pancreas and the liver than in 
other tissues, and that the rat pancreas is able to metabolise ethanol. ${ }^{16}$ In a recent study it was found that ethanol induces a subfamily of cytochrome P-450, which may be an aetiological factor in chronic pancreatitis. ${ }^{17}$ Furthermore, ethanol seems to change the membrane function by altering the protein and lipid constituents of cell membranes, leading to activation of adenylate cyclase or alteration of the microtubular function involved in the secretion of pancreatic enzymes. ${ }^{18}$ Disruption of the integrity of the cell membrane may lead to influx of extracellular calcium and efflux of digestive enzymes, a final pathway for toxic death of the cells. ${ }^{1920}$ Morphometric studies of human pancreas in chronic pancreatitis have shown dilated endoplasmic reticulum and Golgi apparatus, which may correspond with hyperfunctioning of the acinar cell secreting proteins. ${ }^{121}$ This is in accordance with the finding that chronic ethanol intake causes precipitation of protein plugs in the pancreatic duct system. This may be a factor in the production of alcoholic pancreatitis. ${ }^{22}{ }^{23}$ The presence of ethanol in pancreatic juice may further alter the physiochemical properties of the protein rich pancreatic secretions.

Our finding of a higher concentration of ethanol in pancreatic juice than in serum seems to indicate 'secretion' of ethanol by the human pancreas. However, our results apply only to patients with a history of pancreatic disease. This finding is supported by studies showing that the pancreas in chronic pancreatitis can metabolise and probably secrete ethanol due to induction of ethanol inducible cytochrome P-450. We have considered the various interpretations of our findings including systematic analytic error, postoperative changes of either anatomic or physiological nature, and reflux of the alcoholic beverage through the jejunal loop to the drain in the pancreatic duct. Since none of these explanations seems adequate, however, we feel that further clinical investigation is warranted.

We thank The Department of Clinical Chemistry, Bispebjerg Hospital, Copenhagen, Denmark for technical assistance.
1 Noronha M, Bordalo O, Dreiling DA. Alcohol and the pancreas. II. Pancreatic morphology of advanced alcoholic pancreatitis. Am 7 Gastroenterol 1981; 76: 120-4.

2 Kubota K, Magee DF, Sarles H. Biphasic action of intravenous ethanol on dog exocrine pancreatic secretion. Dig Dis Senous ethanol on dog

3 Noel-Jorand MC, Sarles H. Simultaneous mechanism on exocrine pancreatic secretion initiated by alcohol in the conscious dog. Dig Dis Sci 1983; 28: 879-88.

4 Wheatly IC, Barbezeat GO, Hickmann R, Terblance J. The effect of acute ethanol administration on the exocrine pancreatic secretion of the pig. Brf Surg 1975; 62: 707-12.

5 Iwatzuki K, Chiba S. The effect of ethanol on the isolated blood perfused pancreas. F Stud Alchol 1981; 42: 811-3.

6 Fitzpatrick JM, Fitzgerald O, Fitzgerald P, McGeeny KF. A study of ethanol action on the totally isolated canine pancreas. Bull Soc Int Chir 1975; 6: 593-9.

7 Oda $M$. The onset and natural course of chronic alcoholic pancreatitis. Gastroenterol fpn 1979; 14: 628-30.

8 Widmark EMP. Die theoretischen Grundlagen und die praktische Vervendbarkeit der gericht-medizinischen
pritis Alkoholbestimmung. Berlin: Urban und Schwarzenberg, 1932.

9 Bradley JV. Distribution-free statistical tests. Englewood Cliffs: Prentice-Hall, 1968

$10 \mathrm{Kissin}$ B, Begleiter H. Absorption, diffusion, distribution and elimination of ethanol: effects on biological membranes. In: The biology of alcoholism. Vol 1, Biochemistry. New York: Plenum Press, 1971

11 Beck IT, Paloschi GB, Dinda PK, Beck M. Effect of intragastric administration of alcohol on the ethanol concentrations and osmolality of pancreatic juice, bile and portal and tions and osmolality of pancreatic juice, bile and porta

12 Eibel H. Über den Alkoholgehalt des Speichels. Disch Z Ges Gerichtl Med 1949; 39: 538-40.

13 Schmidt DN. Does ethanol exert its effect on the canine pancreas by mediation of cholinergic nerves? Scand $\mathcal{F}$ Gastroenterol 1986; 21 (suppl 126): 69-74

14 Schaffalitzsky de Muckadell OB, Fahrenkrug J, Holst JJ, Lauritzen KB. Release of vasoactive intestinal polypeptide by intraductal stimuli. Scand $\mathcal{F}$ Gastroenterol 1977; 12: 793-9.

15 Mott C, Sarles H, Tiscornia O, Gullo L. Inhibitory action of alcohol on human exocrine pancreatic secretion. Dig Dis 1972; 17: $902-10$.

16 Estival A, Clemente F, Ribet A. Ethanol metabolism by the rat pancreas. Toxicol Appl Pharmacol 1981; 61: 155-65.

17 Acheson DWK, Hunt LP, Rose P, Houston JB, Braganza JM. Factor contributing to the accelerated clearance of theophylline and antipyrine in adults with exocrine pancreatic disease. Clin Science 1989; 76: 377-85.

18 Singh M. Ethanol and the pancreas. In: Go LW, Brooks F, Dimaro EP, Gardner JD, Lebenthal E, Sheele GA, eds. The exocrine pancreas: biology, pathobiology and diseases. New York: Raven Press, 1986: 423-42.

19 Schanne FAX, Kane AB, Young EE, Falker JL. Calcium dependence of toxic cell death: a final common pathway. Science 1979; 206: 700-2.

20 Harvey MH, Cates M, Reber HA. Possible mechanism of acute pancreatitis induced by ethanol. Am $\mathcal{F}$ Surg 1988; 155: 49-56.

21 Tasso F, Stemmelin N, Sarles H, Clop J. Comparative morphometric study on the human pancreas in its normal state and in primary chronic calcifying pancreatitis. Biomedicine 1973; 18: $134-44$.

22 Sarles H, Tiscornia O, Palasciano G. Effects of chronic intragastric ethanol administration on exocrine pancreatic secretion. Scand $\mathcal{F}$ Gastroenterol 1973; 8: 85-6.

23 Payan H, Sarles H, Demwirdjian M. Study of the histological features of chronic pancreatitis by correspondence analysis. Identification of chronic calcifying pancreatitis as an entity. Rev Eur Etud Clin Biol 1972; 17: 663-70. 